\title{
Hemispheric lateralization of the corticostriatal glutamatergic system in the rat
}

\author{
Christine Capper-Loup · Dominik Rebell · \\ Alain Kaelin-Lang
}

Received: 31 March 2009/Accepted: 3 July 2009/Published online: 21 July 2009

(C) Springer-Verlag 2009

\begin{abstract}
Little is known about hemispheric lateralization of subcortical structures. Here, we show a higher expression of the subunit NR2A of the NMDA receptor mRNA in the striatum and of vGluT1 mRNA in the cingulate cortex, in the left hemisphere compared to the right one. This suggests a lateralization of the glutamatergic cortico-subcortical system, at the level of postsynaptic receptors as well as at the level of corticostriatal projections. Such lateralization could play a role in asymmetric diseases like Parkinson's disease.
\end{abstract}

Keywords Lateralization - Striatum · Cortex ·

Glutamate $\cdot$ NMDA receptor $\cdot$ vGluT1

\section{Introduction}

Functional cerebral asymmetries have been first described by Broca (1865). In right-handed people, the left hemisphere is usually dominant for language and logical processing, while the right hemisphere is dominant for spatial attention (Geschwind and Miller 2001). The concept of cortical lateralization is well established, but lateralization of subcortical structures is less clear. We have recently described a specific lateralization of the striatal direct pathway, with a predominance of the left striatum, related to non-motor function (Capper-Loup and Kaelin-Lang 2008). The striatum is the major input structure of the basal ganglia (Albin et al. 1989; Graybiel et al. 1994). It receives

C. Capper-Loup · D. Rebell · A. Kaelin-Lang $(\bowtie)$

Department of Neurology and Department of Clinical Research, Inselspital, Bern University Hospital, University of Bern, Bern, Switzerland

e-mail: alain.kaelin@dkf.unibe.ch convergent afferents from two main sources. Glutamatergic input from the cortex and dopaminergic input from the substantia nigra terminate mainly on inhibitory $\gamma$-aminobutyric acid (GABA)-ergic medium spiny projection neurons (Dube et al. 1988; Graybiel 1990; Parent and Hazrati 1995). Glutamate and dopamine mutually interact at both pre- and postsynaptic levels (Carlsson and Carlsson 1990).

Corticostriatal excitatory glutamatergic inputs are mediated through both ionotropic and metabotropic glutamate receptors. Ionotropic receptors are classified as $N$-methylD-aspartate (NMDA) or non-NMDA [ $\alpha$-amino-3-hydroxy5-methyl-4-isoxasolepropionic acid (AMPA)/kainate] receptors, depending on their pharmacology (Danbolt 2001). NMDA receptors play a major role in the corticostriatal pathway and are implicated in a variety of neurologic disorders, like Parkinson's disease (PD) (Dingledine et al. 1999). In particular, they interact with dopaminergic inputs (Betarbet et al. 2004). The NMDA receptor is composed of protein subunits from two families: the NR1 and NR2 families. The presence of a NR1 subunit is mandatory to express a functional receptor while the NR2 subunits are important to determine receptor subtype binding pharmacology (Buller et al. 1994). The NR2 family is subdivided into NR2A-D subunits. There is a predominance of subunits NR2A and NR2B on striatal projection neurons (Standaert et al. 1999).

The hypothesis of the present study is that the lateralization of striatal direct pathway is due to a lateralization of glutamatergic corticostriatal projection. We compared the expression of NR1, NR2A and NR2B mRNA subunits of the postsynaptic NMDA receptor in the right and left striatum of healthy rats. We also analyzed the expression of the vesicular glutamate transporter 1 (vGluT1) mRNA, a presynaptic component of the corticostriatal projection, in two parts of the cortex known to project to the medial 
striatum: the limbic cingulate cortex $(\mathrm{Cg})$ and the medial agranular cortex (AGm), an association premotor cortex, as well as in the primary motor cortex (M1), to test whether the presynaptic part of the glutamatergic corticostriatal projection was also lateralized.

\section{Materials and methods}

For this study, we used nine healthy adult female SpragueDawley rats that were handled for 4 weeks before being killed by decapitation (Capper-Loup and Kaelin-Lang 2008). Their brains were rapidly dissected and frozen in isopentane. Frontal sections were prepared using a cryostat microtome and processed for hybridization histochemistry (Kaelin-Lang et al. 2000), with the following sequences of mRNA: NR1 1009-1053, NR2A 567-579, NR2B 557-572 and vGluT1 975-928. Quantification of gene expression was performed with the film autoradiograms using the public domain NIH Image program, as described previously (Capper-Loup and Kaelin-Lang 2008). For each rat, we chose four sections at the level of rostral striatum and used the mean of these four sections. On each section, we analyzed the striatum divided into two sectors medial and lateral, and three different parts of the cortex, $\mathrm{Cg}, \mathrm{AGm}$ and M1. Transmission values were calculated as a percentage of the mean value obtained in the lateral sector of the left striatum or in the left cortex averaged across all rats. Statistical evaluation of the results was done using ANOVA for repeated measures, with sector and side as within subject factors followed by paired $t$ tests as post hoc comparisons. Analyses were performed with SPSS software (SPSS, Inc., Chicago, IL). Level of significance was set to $p<0.05$.

\section{Results}

NR2A mRNA expression was higher in the lateral sector than in the medial one on both sides (Fig. 1a); there was a significant effect of the factor 'sector' (ANOVA: $\left.F_{1,8}=220.53 ; p<0.001\right)$. We observed a higher expression of NR2A mRNA on the left striatum, both in medial and lateral sectors. Consequently, there was a significant effect of the factor 'side' too (ANOVA: $F_{1,8}=7.41$, $p<0.05$ ). Furthermore, there was also a significant interaction 'side $\mathrm{x}$ sector' (ANOVA: $F_{1,8}=6.99, p<0.05$ ): the difference of NR2A mRNA expression between the right and left striatum was larger in the medial than in the lateral sector. Post hoc analysis revealed that the right versus left difference was only significant in the medial sector ( $t$ test: medial: $t=-3.418 ; p<0.01$; lateral: $p>0.09)$.
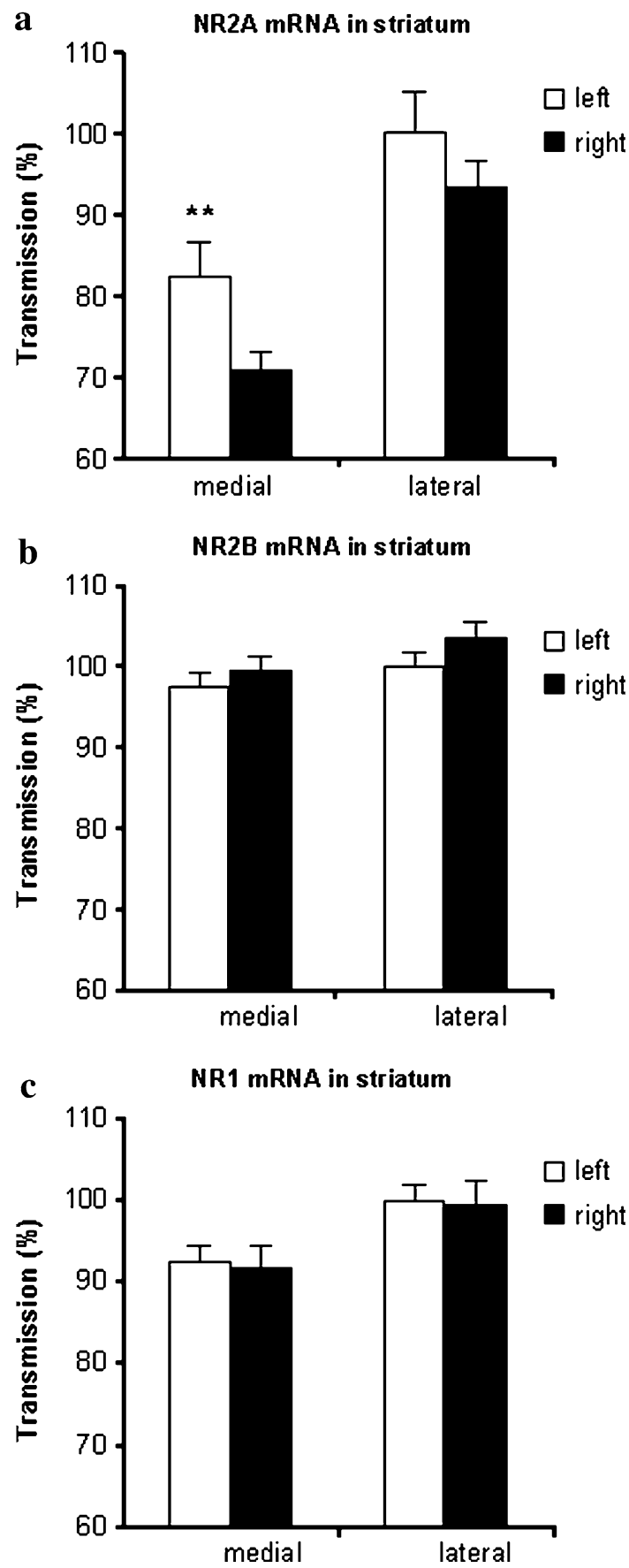

Fig. 1 Percentage of transmission of a NR2A, b NR2B and $\mathbf{c}$ NR1 mRNA expression in the striatum. In the medial sector, NR2A mRNA was significantly higher in the left than in the right striatum. NR2B and NR1 mRNA did not show any significant left versus right difference $(* * p<0.01)$

Expression of NR2B (Fig. 1b) and NR1 (Fig. 1c) mRNA was also higher in the lateral sector than in the medial one with a significant effect of the factor 'sector' (ANOVA: NR2B: $F_{1,8}=9.25 ; p<0.05 ;$ NR1: $F_{1,8}=119.79 ; p<$ 0.001). But we did not observe any difference between the 
right and left striatum neither with NR2B (Fig. 1b) nor NR1 (Fig. 1c) mRNA (ANOVA 'side': NR2B: $p>0.06$; NR1: $p>0.6$; 'sector x side': NR2B: $p>0.4$; NR1: $p>0.9$ ).
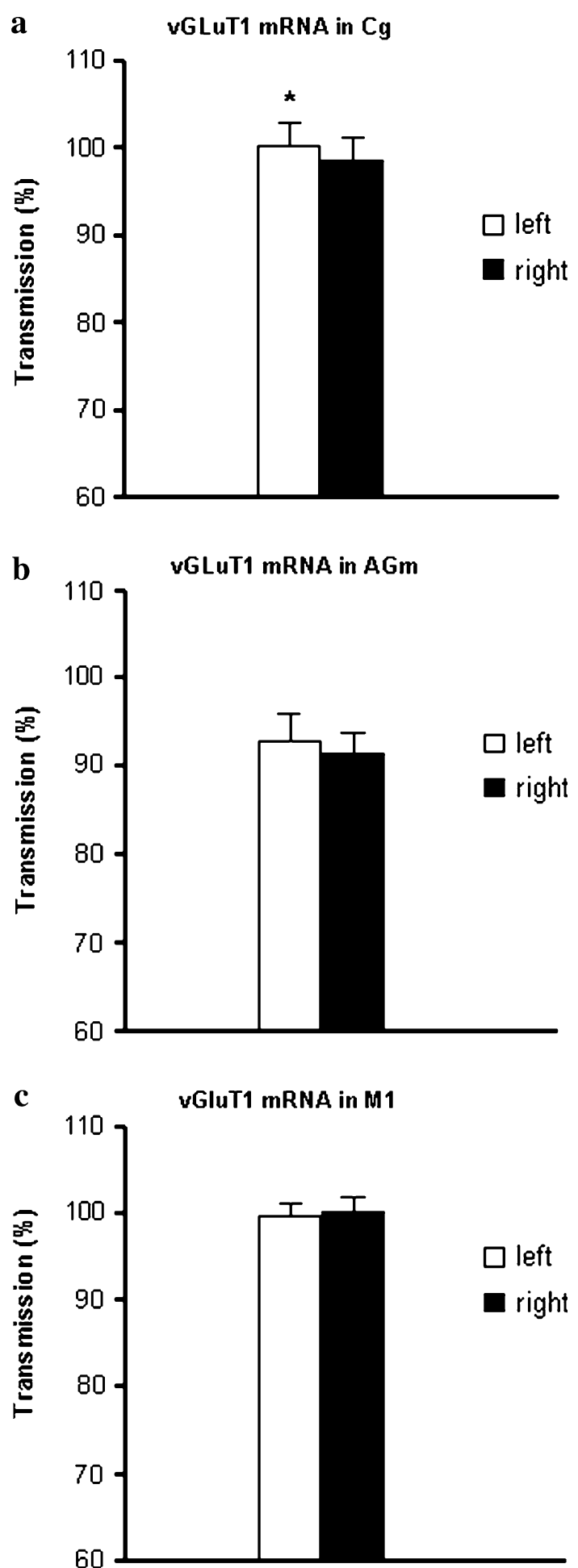

Fig. 2 Percentage of transmission of vGluT1 mRNA expression in the a cingulate cortex, $\mathbf{b}$ medial agranular cortex and $\mathbf{c}$ motor cortex. We observed a significant difference between the left and right vGluT1 mRNA expression only in the cingulate cortex $(* p<0.05)$
In the cortex, the expression of vGluT1 mRNA was higher in the left $\mathrm{Cg}$ compared to the right one (Fig. 2a); there was a significant effect of the factor 'side' (ANOVA: $\left.F_{1,8}=6.01 ; p<0.05\right)$. In contrast, we did not observe any side difference neither in AGm (Fig. 2b) nor in M1 (Fig. 2c); there was no effect of the factor 'side' (ANOVA: AGm: $p>0.3$; M1: $p>0.7$ ).

\section{Discussion}

In the present study we observed a higher expression of NR2A mRNA in the left medial striatum and of vGluT1 mRNA in the left $\mathrm{Cg}$ in healthy rats. This suggests a hemispheric asymmetry in the strength of the cortico-subcortical glutamatergic system. Up to date, little is known regarding such lateralization. Glutamate NMDA-type receptor binding was higher on the left side of the intermediate medial hyperstriatum ventrale of imprinted chicks (Johnston et al. 1995). This hyperstriatum has some efferent connections to structures thought to be involved in the initiation and maintenance of several motor behaviors.

In our study, the lateralization of NR2A mRNA was present only in the medial sector. The medial part of the striatum is mainly related to limbic function, while the lateral part is related to motor function (McGeorge and Faull 1989). This suggests that NR2A mRNA lateralization does not concern motor functions, but limbic ones. The medial striatum receives projections from $\mathrm{Cg}$ and $\mathrm{AGm}$ (McGeorge and Faull 1989). A higher vGluT1 mRNA expression was observed in the left side, only in $\mathrm{Cg}$, also suggesting a limbic implication of the corticostriatal projection lateralization. These observations indicate that the lateralization is not only present in the striatum but also in the cortical region sending projection to the striatum and that it concerns limbic functions. In human, an absence of laterality in frontal cortex and putamen was described, using ${ }^{3} \mathrm{H}-\mathrm{MK}-801$ binding, a NMDA receptor antagonist (Kornhuber et al. 1989). One possible explanation for this difference is that ${ }^{3} \mathrm{H}-\mathrm{MK}-801$ binding shows the results for the entire NMDA receptors, while we found only a lateralization of the NR2A subunit.

In the striatum, medium spiny neurons are divided into two classes: the dynorphin (DYN) positive neurons of the striatal direct pathway and the enkephalin (ENK) positive cells of the striatal indirect pathway (Alexander and Crutcher 1990). In a previous study we found a higher expression of DYN mRNA in the left medial striatum (Capper-Loup and Kaelin-Lang 2008). DYN projection neurons have a stronger NR2A mRNA labeling than ENK projection neurons (Kuppenbender et al. 2000). This suggests that the higher NR2A mRNA expression observed, in the present study, in the medial sector of the left striatum of 
healthy rats represents the lateralization of the striatal direct pathway with a possible relation to limbic function.

Lateralization was not found with the other NMDA receptor subunits, NR2B and NR1 mRNA. As previously mentioned, the NMDA receptor is a heteromeric assembly of NR1 and NR2 subunits (Luo et al. 1997). Other studies have also described segregated changes among the NMDA receptor subunits. In unilateral parkinsonian rat, levels of NR1 and NR2B were reduced in the membrane fractions of lesioned striatum, while level of NR2A stayed unchanged. These differences could arise from a selective decrease in the number of NR1/NR2B complexes (Dunah et al. 2000). Similarly, NR1, NR2A, NR2B and NR2C mRNAs were not all affected in the same way after cocaine exposure (Yamaguchi et al. 2002). The dissociation between levels of the different NMDA receptor subunits points to an independent regulation of these subunits. As functional properties of NMDA receptors depend on their subunit composition, it is likely that selective changes of a subunit will affect glutamatergic transmission and have an effect on the pathophysiology of basal ganglia diseases (Ulas and Cotman 1996). Our study was done with healthy rats, indicating that in a normal situation, NMDA receptor subunits do not present a homogenous distribution. As we used female rats only, we cannot exclude that male rats would present a slightly different pattern of lateralization. Patterns of cerebral cortical lateralization are sex-specific in both human and animal brain (Diamond 1989; Diamond 1991). However, it is not clear whether subcortical lateralization is also gender specific.

\section{Conclusion}

In conclusion, our study demonstrates a lateralization of both the striatal glutamatergic receptors and the cortical presynaptic glutamatergic system, probably related to limbic function, with predominance on the left side. We suggest that this lateralization concerns the direct pathway. Lateralization of the corticostriatal projection of the direct pathway could be implicated in the pathophysiology of asymmetric diseases like PD. Further studies are required to relate this finding to behavior.

Acknowledgments We thank Theres Lauterburg for her technical assistance. This work is supported by a grant from the Swiss Parkinson Foundation to A.K.L.

\section{References}

Albin RL, Young AB, Penney JB (1989) The functional anatomy of basal ganglia disorders. Trends Neurosci 12:366-375
Alexander GE, Crutcher MD (1990) Functional architecture of basal ganglia circuits: neural substrates of parallel processing. Trends Neurosci 13:266-271

Betarbet R, Poisik O, Sherer TB, Greenamyre JT (2004) Differential expression and ser897 phosphorylation of striatal $N$-methyl-Daspartate receptor subunit NR1 in animal models of Parkinson's disease. Exp Neurol 187:76-85

Broca P (1865) Sur la faculte du langage articule. Bull Soc Anat Paris 6:493-494

Buller AL, Larson HC, Schneider BE, Beaton JA, Morrisett RA, Monaghan DT (1994) The molecular basis of NMDA receptor subtypes: native receptor diversity is predicted by subunit composition. J Neurosci 14:5471-5484

Capper-Loup C, Kaelin-Lang A (2008) Lateralization of dynorphin gene expression in the rat striatum. Neurosci Lett 447:106-108

Carlsson M, Carlsson A (1990) Interactions between glutamatergic and monoaminergic systems within the basal ganglia-implications for schizophrenia and Parkinson's disease. Trends Neurosci $13: 272-276$

Danbolt NC (2001) Glutamate uptake. Prog Neurobiol 65:1-105

Diamond MC (1989) Sex and the cerebral cortex. Biol Psychiatry $25: 823-825$

Diamond MC (1991) Hormonal effects on the development or cerebral lateralization. Psychoneuroendocrinology 16:121-129

Dingledine R, Borges K, Bowie D, Traynelis SF (1999) The glutamate receptor ion channels. Pharmacol Rev 51:7-61

Dube L, Smith AD, Bolam JP (1988) Identification of synaptic terminals of thalamic or cortical origin in contact with distinct medium-size spiny neurons in the rat neostriatum. J Comp Neurol 267:455-471

Dunah AW, Wang Y, Yasuda RP, Kameyama K, Huganir RL, Wolfe BB, Standaert DG (2000) Alterations in subunit expression, composition, and phosphorylation of striatal $\mathrm{N}$-methyl-D-aspartate glutamate receptors in a rat 6-hydroxydopamine model of Parkinson's disease. Mol Pharmacol 57:342-352

Geschwind DH, Miller BL (2001) Molecular approaches to cerebral laterality: development and neurodegeneration. Am J Med Genet 101:370-381

Graybiel AM (1990) Neurotransmitters and neuromodulators in the basal ganglia. Trends Neurosci 13:244-254

Graybiel AM, Aosaki T, Flaherty AW, Kimura M (1994) The basal ganglia and adaptive motor control. Science 265:1826-1831

Johnston AN, Rogers LJ, Dodd PR (1995) [3H]MK-801 binding asymmetry in the IMHV region of dark-reared chicks is reversed by imprinting. Brain Res Bull 37:5-8

Kaelin-Lang A, Liniger P, Probst A, Lauterburg T, Burgunder JM (2000) Adenosine A2A receptor gene expression in the normal striatum and after 6-OH-dopamine lesion. J Neural Transm 107:851-859

Kornhuber J, Mack-Burkhardt F, Riederer P (1989) Regional distribution of $[3 \mathrm{H}] \mathrm{MK}-801$ binding sites in the human brain. Brain Res 489:397-399

Kuppenbender KD, Standaert DG, Feuerstein TJ, Penney JB Jr, Young AB, Landwehrmeyer GB (2000) Expression of NMDA receptor subunit mRNAs in neurochemically identified projection and interneurons in the human striatum. J Comp Neurol 419:407-421

Luo J, Wang Y, Yasuda RP, Dunah AW, Wolfe BB (1997) The majority of $N$-methyl-D-aspartate receptor complexes in adult rat cerebral cortex contain at least three different subunits (NR1/ NR2A/NR2B). Mol Pharmacol 51:79-86

McGeorge AJ, Faull RL (1989) The organization of the projection from the cerebral cortex to the striatum in the rat. Neuroscience 29:503-537 
Parent A, Hazrati LN (1995) Functional anatomy of the basal ganglia.

I. The cortico-basal ganglia-thalamo-cortical loop. Brain Res Rev 20:91-127

Standaert DG, Friberg IK, Landwehrmeyer GB, Young AB, Penney JB Jr (1999) Expression of NMDA glutamate receptor subunit mRNAs in neurochemically identified projection and interneurons in the striatum of the rat. Mol Brain Res 64:11-23
Ulas J, Cotman CW (1996) Dopaminergic denervation of striatum results in elevated expression of NR2A subunit. Neuroreport 7:1789-1793

Yamaguchi M, Suzuki T, Abe S, Hori T, Kurita H, Asada T, Okado N, Arai H (2002) Repeated cocaine administration differentially affects NMDA receptor subunit (NR1, NR2A-C) mRNAs in rat brain. Synapse 46:157-169 